\title{
O Twitter como Ferramenta de Obtenção de Vantagem Competitiva: um Estudo Multicaso com Empresas de Comércio Coletivo
}

\author{
Ronnie E. S. Santos ${ }^{1}$, Cleyton V. C. Magalhães ${ }^{1}$, Diego G. S. Santos ${ }^{1}$, Roberto \\ Cássio S. Nascimento ${ }^{1}$, Jorge S. Correia Neto ${ }^{2}$ \\ ${ }^{1}$ Unid. Acad. de Serra Talhada- Univ. Federal Rural de Pernambuco (UAST/ UFRPE) \\ Fazenda Saco, s/n - CEP: 56.900-000 - Serra Talhada - PE - Brazil \\ ${ }^{2}$ Unid. Acad. de Educação a Distância - Univ. Federal Rural de Pernambuco (UFRPE) \\ Rua Dom Manoel de Medeiros, s/n, Dois Irmãos - CEP: 52171-900 - Recife/PE - Brazil \\ \{cleyton.vanut, ronnie.gd, jorgecorreianeto\}@gmail.com, \\ robertocassio@hotmail.com
}

\begin{abstract}
The collective-commerce sites and the social networks sites have grown exponentially in the competitive Brazilian market, which demands new strategies for customer relationship. Thus, this study aimed to describe elements of the strategy implemented by collectively-commerce sites to achieve competitive advantage on the Internet via Twitter, based on the model of Hart and Milstein (2003). Initial results consider the messages sent over the network by the three largest collective-commerce sites in Brazil in the first quarter of 2011, showing that Twitter as social media is able to generate some competitive advantages for companies that use it, but focusing more on the internal dimension.
\end{abstract}

Resumo. Os sites de comércio coletivo e as redes sociais têm crescido exponencialmente no competitivo mercado brasileiro, o que demanda novas estratégias de relacionamento com o cliente. Assim, este trabalho objetivou descrever elementos da estratégia aplicada por empresas de comércio coletivo para a obtenção de vantagem competitiva através do Twitter, com base no modelo de Hart e Milstein (2003). Os resultados iniciais consideram as mensagens enviadas através da rede pelas três maiores empresas de comércio coletivo do Brasil no primeiro trimestre de 2011, mostrando que o Twitter como mídia social é capaz de gerar algumas vantagens competitivas para as empresas que o utilizam, porém com um foco maior na dimensão interna.

\section{Introdução}

O e-commerce é um tipo de negócio cujas atividades comerciais são providas e sustentadas através de redes de comunicação como a internet (MEIRA JR. et al., 2002). Este tipo de atividade comercial permite que produtos e serviços sejam oferecidos a clientes presentes em ambientes geograficamente afastados da empresa. Em 2010, a modalidade de comércio eletrônico que atingiu grande popularidade no Brasil foram os chamados sites de compra coletiva.

A Compra Coletiva é um modelo de e-commerce cuja dinâmica consiste em vender produtos e serviços para um número mínimo pré-estabelecido de consumidores por oferta (GAVIOLI, 2011). A proposta dos sites é oferecer grandes promoções em 
produtos e serviços, que geralmente não são oferecidos por outros sites de comércio eletrônico, com descontos que podem atingir até $90 \%$, sendo que os lucros são gerados através no volume de produtos vendidos, e não com o valor propriamente dito.

Um dos principais elementos que tem viabilizado o crescimento acelerado do comércio coletivo na Internet são redes sociais. Diversas pesquisas mostram que as redes sociais têm influenciado na decisão de compra dos usuários de internet no Brasil e representam um grande centro de divulgação de produtos e serviços (B.I. INTERNATIONAL WEBSITE, 2011).

Entre as redes sociais mais populares da web, o Twitter foi uma das mídias que apresentou um crescimento bastante expressivo nos últimos anos. Segundo pesquisa do E-Commerce News (2011), o número de usuários brasileiros na rede cresceu 20,5\% até julho de 2010 em relação ao mesmo período de 2009.

Em relação ao marketing digital, o Twitter também é a rede de maior preferência entre as empresas. Uma matéria publicada no Jornal The New York Times mostrou que uma postagem neste site pode em teoria ser visto por milhões de pessoas torando-se mais eficiente que um email ou um telefonema, em certas circunstâncias (ORLIKOWSKI; THOMPSON, 2010). Esse estudo procurou entender quais estratégias, abordagens e aplicações poderiam ajudar uma empresa específica a gerar benefícios e estratégias competitivas sustentáveis para o negócio, considerando principalmente suas estratégias de customer relationship management (CRM) através do Twitter.

A estratégia competitiva visa estabelecer uma posição lucrativa e sustentável da empresa contra as forças que determinam a concorrência da indústria (PORTER, 1990). Hart e Milstein (2003) discutem o fato de a sustentabilidade estar sendo vista por muitas empresas como uma oportunidade estratégica de negócio, abrindo caminho para a diminuição de custos e riscos, ou até mesmo elevando seus rendimentos e sua participação de mercado por meio da inovação.

O grande marco da visão interna da firma ocorreu com a obra da economista Penrose, em 1959 (PENROSE, 2006). A autora percebeu que para enfrentar as forças externas à organização e para manter a taxa de crescimento, era necessário ter recursos e capacidades significativos. Barney (1991) vai além, afirmando que para se alcançar a vantagem competitiva, os recursos não apenas precisam ser heterogêneos e imóveis, mas, também valiosos, raros, insubstituíveis e inimitáveis (VRII). Mais recentemente, foi retirado o critério de ser insubstituível e incluída a necessidade de organização dos recursos (VRIO) (BARNEY, 2002). Barney (2002) explica que capital financeiro, físico, humano e organizacional são categorias de recursos. As capacidades são atributos internos da empresa que permitem a coordenação e exploração dos recursos, enquanto as competências viabilizam as estratégias de diversificação corporativa.

Quanto ao modelo de valor ao acionista, Hart e Milstein (2003) afirmam que é um construto bidimensional. $\mathrm{O}$ eixo vertical reflete a necessidade simultânea que a empresa tem de manter os negócios atuais e de criar a tecnologia e os mercados de amanhã. $\mathrm{O}$ eixo horizontal reflete a necessidade de crescimento e de proteção das habilidades e potenciais organizacionais internos, e, ao mesmo tempo, de infundir na empresa novas perspectivas e conhecimentos vindos de fora. Neste modelo a justaposição dessas duas 
dimensões produz uma matriz com quatro dimensões distintas para a geração de valor ao acionista: Custo, Reputação, Inovação e Crescimento (Figura 1).

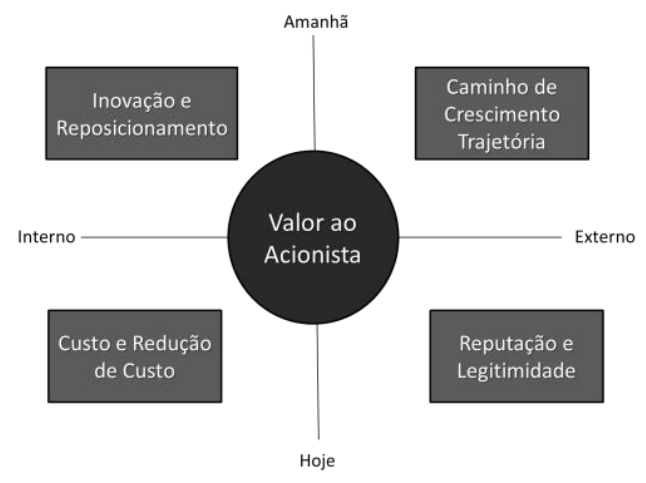

Figura 1. Dimensões do Modelo de Valor ao Acionista. Fonte: Hart e Milstein (2003).

Assim, se coloca a seguinte pergunta de pesquisa: quais são os elementos da estratégia aplicados por empresas de comércio coletivo para a obtenção de vantagem competitiva na internet através do Twitter, considerando o envolvimento com cliente como uma importante ferramenta da criação de valor para o negócio e consequentemente o aumento nos lucros da empresa? Os resultados desta pesquisa trazem uma análise de mensagens postadas no Twitter pelas três maiores comércio coletivo do país, durante o primeiro trimestre de 2011 considerando as quatro dimensões do modelo de criação de valor ao acionista proposto por Hart e Milstein (2003).

\section{Procedimentos Metodológicos}

O método de pesquisa utilizou uma abordagem mista (quantitativa e qualitativa), de caráter exploratório-descritivo, utilizando um estudo de casos múltiplos com os três maiores sites de compra coletiva do país.

O estudo exploratório é definido como uma pesquisa que tem por objetivo proporcionar maior familiaridade com um problema, a fim de torná-lo mais explícito, principalmente ao tratar-se de um tema pouco investigado ou que não tenha sido abordado anteriormente (LUCIANO; TESTA; ROHDE, 2007). O estudo de caso é uma inquirição empírica que investiga um fenômeno contemporâneo, quando a fronteira entre o fenômeno e o contexto não é claramente evidente e onde múltiplas fontes de evidência são utilizadas (YIN, 1989).

Foram coletadas todas as mensagens (tweets) postadas no perfil do Twitter dos três maiores ambientes virtuais de comércio coletivo do país (BOLSA DE OFERTAS, 2011), respeitando o intervalo entre primeiro de janeiro e trinta e um de março de 2011. O período de tempo considerado pela pesquisa forneceu uma quantidade de dados aceitável para uma análise inicial da estratégia aplicada pelas empresas para a obtenção de vantagem competitiva na internet através do Twitter.

Depois de armazenadas, as postagens tiveram o seu conteúdo analisado de acordo com a classificação de CRM Social proposto por Orlikowski e Thompson (2010), que tem como base as dimensões de Hart e Milstein (2003), visualizado na tabela abaixo (Tabela 1). A análise de conteúdo aplicada nesta etapa é uma técnica de estudo de 
linguagem para análise de discursos diversos, através de uma abordagem qualitativa e quantitativa da incidência de palavras e elementos de texto, possuindo instrumentos metodológicos suficientes para assegurar a objetividade, sistematização e influência aplicadas aos discursos (SARRIERA et al., 2003).

Tabela 1. CRM Social X Modelo de Valor ao Acionista.

\begin{tabular}{|c|c|}
\hline Dimensão & Finalidade da Postagem \\
\hline Custo & Propaganda, preço, desconto, oferta \\
\hline Reputação & $\begin{array}{l}\text { Notícias externas, campanhas, } \\
\text { agradecimentos, auxílio, saudações }\end{array}$ \\
\hline Inovação & $\begin{array}{l}\text { Serviços de atendimento, convites, outras } \\
\text { postagens diretas }\end{array}$ \\
\hline Crescimento & Pesquisas, enquetes, concursos, opiniões \\
\hline
\end{tabular}

\section{Resultados}

Através do armazenamento das mensagens coletadas no período considerado pela pesquisa, pode-se inferir que a empresa $\mathrm{C}$, terceira maior em comércio coletivo no país, foi a que mais realizou postagens na rede, com um total de 540 envios. Isso representa uma maior interação com os clientes através da rede social. Cada mensagem enviada pela empresa $C$ poderia em tese atingir mais de 87 mil pessoas que a acompanham na rede social. O termo "em tese" refere-se ao fato de que todas as mensagem ficam visíveis na página de todos os seguidores, mas isso não significa que todos estarão online para vê-la no momento do envio.

Neste mesmo sentido a empresa B, segunda maior do ramo, foi a que menos utilizou as ferramentas do Twitter para postagem de informações sobre produtos e serviços e comunicação com clientes. Durante o período compreendido pela pesquisa o perfil enviou 349 mensagens, atingindo em teoria 74 mil pessoas.

Por fim, a empresa A, líder em comércio coletivo no Brasil, possui pouco mais de 21 mil seguidores e efetuou 414 postagens na rede, durante o período analisado no estudo.

Através da análise e classificação do conteúdo escrito nas mensagens enviadas, podese perceber o direcionamento de foco de cada empresa estudada sobre as dimensões do modelo de valor ao acionista (Figura 2).

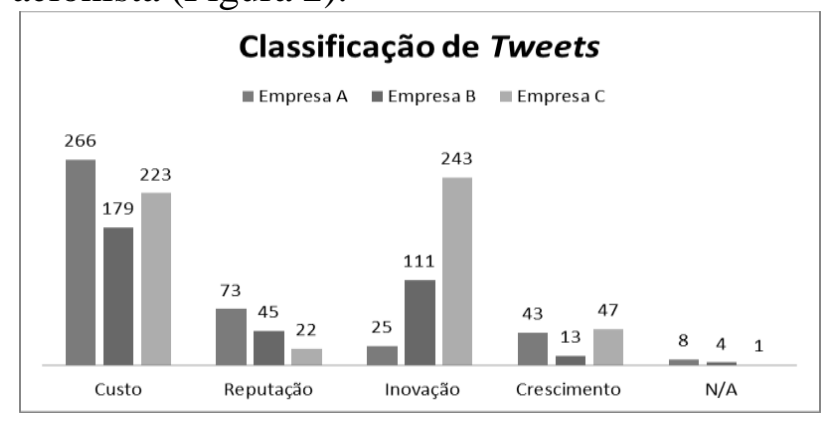

Figura 2. Resultado da classificação das postagens

A Figura 2 mostra que através das mensagens trocadas pelo Twitter, durante o primeiro trimestre de 2011, as empresas estiveram focadas principalmente na divulgação e apresentação dos seus serviços, buscando vantagem competitiva com a oportunidade de realizar uma única postagem disponível para grande número de clientes, proporcionando reduções significativas de custos. 
No entanto, na empresa $\mathrm{C}$, o foco prioritário não foi exclusivamente o contexto que envolve os custos, mas também o de criar maneiras inovadoras que pudessem aproximála do seu cliente, através de mensagens direcionadas particurlamente para um dado usuário, seja para oferecer serviços ou responder perguntas relacionadas ao site. A dimensão inovação também foi explorada pela empresa B (segunda maior), mas não foi considerada tão importante pela empresa A (líder do mercado), que não utilizou a mídia social como meio de relacionamento com clientes de forma individual, mas principalmente de maneira unidirecional, geral e coletiva.

No campo Reputação e Legitimidade, a empresa A direcionou parte de suas postagens visando agregar valor à sua marca através de campanhas de cunho social, e uma parte maior a campanhas publicitárias associando as mensagens a meios externos ao Twitter, mostrando para os usuários a sua popularidade em outros ambientes. A empresa B também realizou trabalhos buscando aumentar a sua identidade com os clientes na rede social, e tal processo esteve envolvido principalmente com ações do tipo social e de característica cotidiana. A empresa $\mathrm{C}$ foi a que mais desconsiderou a exploração deste campo.

A dimensão Crescimento e Trajetória foi a menos visada pelas maiores empresas pesquisadas. Neste contexto, mesmo que reduzidamente, a empresa $\mathrm{C}$ foi a que esteve mais preocupada com a comunicação direta com os usuários, visando fidelização por meio de enquetes e pesquisas através da rede. De modo semelhante a empresa A também dedicou tempo principalmente para encorajar os seus consumidores a compartilhar experiências, além de realizar pesquisas para aumentar o seu conhecimento sobre o perfil dos consumidores e concursos para estimular a interação entre os clientes. A empresa B realizou menos atividades que promovessem conhecimento sobre a opinião dos seus clientes.

\section{Conclusões}

Os resultados desta pesquisa mostram que o Twitter é uma mídia social capaz de agregar vantagens competitivas para as empresas, possibilitando redução de custos e possibilidade de crescimento com benefícios sustentáveis. No caso particular das empresas do ramo de comércio coletivo, esta rede social possui uma característica bastante semelhante à do negócio: a interação em tempo real. Por isso, pode-se aumentar a eficiência desta estratégia permitindo que o público obtenha informações sobre as ofertas e promoções dos sites que possuem um ponto definido de início e fim.

As empresas analisadas viram no Twitter principalmente a oportunidade de redução de custos com propagandas e serviços de atendimento ao cliente, obtendo também dados importantes que podem ser fonte inovadora de estratégias futuras. Pode-se concluir em seguida que a mídia não foi vista ainda como uma oportunidade crescimento em relação à legitimidade, identidade e marca da empresa, assim como às estratégias de legitimidade e conhecimento do perfil e características do público.

Assim, considera-se que as empresas trabalharam principalmente no que se refere às estratégias de dimensão de ambiente interno, deixando as que se referem ao ambiente externo por segundo plano. No entanto, deve-se atentar que o negócio deve possuir desempenho simultâneo em todos os quatro quadrantes do modelo, e em uma base contínua, caso deseje maximizar o valor ao acionista ao longo do tempo. 
Como trabalhos futuros pretende-se montar uma base maior de dados que contemplem não só as mensagens enviadas pelas empresas, mas também as postadas pelos clientes, de forma a construir uma estrutura que permita descobrir conhecimento na base de dados e oferecer apoio às decisões que visem alcance de vantagens estratégicas em mídias sociais e ambientes web.

\section{Referências}

B .I. INTERNATIONAL. (2001) "O poder de influência das Redes Sociais no $E$ commerce". Acesso em: 01 maio 2011. Disponível em: http://bit.ly/liOGpT.

BARNEY, J. B. (1991) Firm resources and sustained competitive advantage. Journal of Management, v. 17, n. 1, p. 99-120.

BARNEY, Jay B. "Gaining and Sustaining Competitive Advantage". 3. ed. New Jersey: Prentice-Hall, 2002.

BOLSA DE OFERTAS. (2011) “Oferta Única é o quarto maior site de compra coletiva do Brasil”. Disponível em: http://bit.ly/GHe8Tg Acesso em: 01 maio 2011.

E-COMMERCE NEWS. (2011) "Brasil é o $2^{\circ}$ em crescimento do Twitter". Acesso em: 01 abr. 2011. Disponível em: http://bit.ly/GDhKKs.

ENCARNAÇÃO, B. P. A. (2010) "Emergência das Máquinas Sociais na Web, O Caso Futweet". Universidade Federal de Pernambuco. Tese de Mestrado.

GAVIOLI, G. "E-Commerce News: Compra Coletiva". (2011) Acesso em: 01 maio 2011. Disponível em: http://bit.ly/bsMtJg.

HART, S.L.; MILSTEIN, M.B. (2003) Criando Valor Sustentável. RAE Executivo, São Paulo, v.3, n², p. 65-79, 2004. Tradução Pedro F. Bendassolli. Artigo originalmente publicado na Academy of Management Executive, v. 17, n. 2, p. 56-69.

LUCIANO, E. M.; TESTA, M. G.; ROHDE L. R. (2007) Gestão de Serviços de Tecnologia da Informação: Identificando a Percepção de Benefícios e Dificuldades para a sua Adoção. Anais... Anais do XXI EnANPAD, Rio de Janeiro, RJ.

MEIRA JR., W.; MURTA, C. D.; CAMPOS, S. V. A.; GUEDES NETO, D. O. (2002) "Sistemas de Comércio Eletrônico - Projeto e Desenvolvimento". Editora Campus: Sociedade Brasileira de Computação.

ORLIKOWSKI, W.; THOMPSON, S. (2010) Leveraging Social Media For Customer Engagement: An Experiment At BT. Center for Information Systems Research. Massachusetts Institute of Technology.

PENROSE, E. (2006) “A teoria do crescimento da firma”. Campinas-SP: Ed. Unicamp.

PORTER, M. E. (1990) "Vantagem competitiva: estratégia competitiva - os conceitos centrais". Rio de Janeiro: Campus.

SARRIERA, J. C.; MOREIRA, M. C.; ROCHA, K. B.; BONATO, T. N.; DUSO, R; PRIKLADNICKI, S. (2003) Paradigmas em psicologia: compreensões acerca da saúde e dos estudos epidemiológicos. Revista Psicologia Social. v. 15, n. 2. Porto Alegre-RS.

YIN, Robert K. (1989) “Case Study Research - Design and Methods”. USA: Sage Pub. 